\title{
Study on the Development and Inheritance of Traditional Martial Art from Physical Education Teaching Reform in Colleges and Universities
}

\author{
Defang Chen
}

Nanchang Institute of Science \& Technology, Nanchang 330108, China

Keywords: colleges and universities; physical teaching; martial art; spiritual inheritance

\begin{abstract}
With the development of our social economy, martial art is also facing opportunities and challenges. Under the trend of economic globalization, the development of martial art education in senior school is the key issue in the reform of physical education in colleges and universities. Problems existing in martial art teaching also gradually appear, such as routine and gymnastic teaching, which seriously decreases students' interest in learning martial art and makes it difficult to promote development as well as inheritance in colleges and universities. Physical education is an important base for the development and inheritance of traditional martial art. To carry out scientific and efficient martial art teaching activities will improve teaching quality. This paper briefly analyzes the development and inheritance of traditional martial art from the perspective of physical teaching reform in colleges and universities, and then puts forward specific teaching strategies, hoping to promote further innovation of martial art teaching.
\end{abstract}

\section{Introduction}

With a long history, Martial Art is a kind of sports item influenced by Chinese traditional culture, embodying a high-level culture. Due to the gradual development of social economy, the environment and culture on which Martial Art depends for its survival and development have changed a lot. In addition, since our country has been influenced by western competitive ideas in recent years, inheritance and development of Martial Art have also become an urgent concern. Colleges and universities are important bases for traditional Martial Art's inheritance and development. Carrying out scientific and efficient teaching activities can promote its development and inheritance.

\section{Current Status of Martial Art Education in Colleges and Universities}

Martial Art is a kind of physical activity, containing a wealth of philosophies, strengthening people both mentally and physically, and carrying forward traditional culture. But in recent years, there are some difficulties to develop the ameliorated Martial Art on the campus. Martial Art teaching is a part of the teaching contents of physical education in colleges and universities. However, influenced by western theories related to physical education, bad phenomenon also appeared during the development, such as blindly copy and imitation, which deviate from the foundation of the development of traditional culture in our country. At present, the teaching of Martial Art in colleges and universities is shouldering an important task of cultivating talents. If the traditional teaching method or imitating teaching method according to western sports items is still adopted, the quality of talent training will inevitably be affected and the development of Martial Art teaching will be restricted.

Since our country joined WTO organization, the market economy has been developing rapidly. The national quintessence of our country -Martial Art, also faces unprecedented impacts and challenges. Under this kind of development background, to develop Martial Art education in colleges and universities has become a key research topic. Due to some students' low interest, coupled with routine and gymnastic Martial Art teaching as well as other phenomena, it is difficult to effectively inherit and carry forward the value of Martial Art teaching. After analysis, we found it is mainly due to a lack of traditional Martial Art teaching contents in Martial Art education in 
colleges and universities. Moreover, the teaching mainly draws lessons from western competitive sports rules and is under the guidance of government and ignores to carry out traditional Martial Art teaching activities, attaching too much importance to competitive Martial Art. At present, most teaching contents are primary long boxing, primary sword, primary stick or simplified Tai Chi but neglect many outstanding traditional Martial Arts, such as Eight Fixed Palms, Chen's Tai Chi, arm fist boxing and so on. Now, Martial Art teaching blindly pursues competitive education, leaving a negative effect on the development and inheritance of traditional Martial Art teaching.

Less attention paid to Martial Art teaching from colleges and universities restricts and hinders its development. Due to a lack of perfect, scientific and reasonable teaching system, Martial Art facilities are simple, capital investment is relatively small, construction of teachers is insufficient and teaching materials are blindly copied, all of which make the development of Martial Art teaching in colleges and universities slow, decrease students' interest in classroom learning and change teachers to be perfunctory. Because there isn't enough attention attached to Martial Art teaching, colleges and universities do not stress the construction of professional Martial Art teachers. As a result, Martial Art teaching is in a state of disorder. Some teachers' skills and cultural quality are in a low level, failing to meet the diversified learning needs of students. Most teachers are not mainly from Martial Art department, that is, they are not graduates of physical education department of colleges and universities and have not received postgraduate education, which makes the colleges and universities lack high-quality Martial Art teacher resources.

There is a lack of cultural appeal and a series of problems in Martial Art teaching when Martial Art education and cultural education are divided. Because of the influence from western competitive thoughts, Korean taekwondo, Japanese judo and other Martial Art items gradually aroused the interest of students. However, free combat of our country is not popular. So it can be seen that foreign Martial Art has a certain impact on our Martial Art culture, hindering the further development and extension. At present, colleges and universities have ameliorated the Martial Art education mode in combination with the development of Martial Art abroad. It moves towards the stage of "High, New, Difficult and Beautiful". Compared with competitive and gymnastic items, Martial Art has lost countless values and it also makes Martial Art become gymnastic, which is mainly due to the loss of connotation of traditional culture, coupled with the division between Martial Art education and cultural education in colleges and universities. In the process of teaching, too much emphasis is attached to routine teaching, while the connotation of Martial Art culture and value can not be showed and the charm of teaching is reduced. The repeated single teaching contents erase students' learning enthusiasm and also affect the quality and effectiveness of Martial Art teaching.

Martial Art teaching activities in colleges and universities are mainly based on the contents of teaching materials. However, the contents of teaching materials are out-dated, which lags the development of Martial Art teaching and reduce students' interest in improve their learning. The present contents are mainly about competition referees, and lack the introduction of fusion technologies of theoretical knowledge. Besides, the contents are old and single, which are difficult to combine with the times, failing to reflect college students' development characteristics. The contents of Martial Art materials ignore the diversified development needs of students, leading to a phenomenon that more and more students prefer Martial Art, but dislike Martial Art courses.

According to the guidelines issued by the Ministry of Education, ordinary colleges and universities should formulate a unified curriculum syllabus and talents cultivation goals of Martial Art. In order to improve the quality of teaching, colleges and universities strictly implement teaching plans, adopt unified standards to carry out Martial Art teaching and strictly require students' technical movements. However, it results into a pathetic stereotyped reality by cultivating students' ability to learn Martial Art, but failing to attach importance to the culture accomplishment, which has caused a lack of Martial Art talents in the market. Because of competitive Martial Art, more and more talents are educated, but the heirs of traditional Martial Art and regional characteristics are decreasing gradually. Colleges and universities excessively pursue the unity of training goals, restrain the individualized development of students, and ignore the cultivation of 
creativity and the exploration of potential. This has made it difficult for most graduates to adapt to changes in the market.

\section{Development and Inheritance of Traditional Martial Art from the Perspective of Physical Education Teaching Reform in Colleges and Universities}

In order to develop Martial Art teaching in colleges and universities, we must pay more attention to Martial Art teaching. By stimulating students' interest, innovating and optimizing teaching methods, strengthening the training of Martial Art teachers for professional theoretical knowledge as well as skills, we will be able to improve the faculty, promote the construction of teachers and accurately position teaching objectives. In view of the current situation of Martial Art teaching, it is possible to promote the sustainable development of Martial Art and culture, and promote its inheritance and development by taking reasonable measures. First of all, we are supposed to strengthen the reform of physical education teaching in colleges and universities. Because Martial Art is an excellent traditional culture in our country, strengthening Martial Art education can highlight the development and inheritance of Martial Art culture, which is also a short way. At present, Martial Art education in colleges and universities in China pays too much attention to students' study of Martial Art skills and techniques, but neglects their grasp of cultural connotation. Martial Art teaching activities are too dull and rigid, so in the teaching reform, we should enhance the understanding of Martial Art culture teaching, reposition the objectives of Martial Art education and integrate the contents of Martial Art culture into Martial Art teaching objective system, so that students will be able to understand the basic culture of Martial Art and promote the development and inheritance of traditional Martial Art at the same time.

It is an effective way for Martial Art teaching to inherit and carry forward the cultural connotation by integrating traditional Martial Art teaching contents into Martial Art teaching in colleges and universities. To carry out practical teaching activities, we are supposed to strengthen the follow-up teaching reform, fully combine teaching with the long - range and regional character reflected in the process of traditional Martial Art' formation and development, establish the traditional Martial Art teaching system, realize the construction of higher education and Martial Art education system, strengthen Martial Art courses, meet the long-term and continuous curriculum requirements and ensure a concentrated curriculum. In order to save teaching resources, some colleges and universities stipulate that only students at first grade are allowed to select Martial Art course or Martial Art teaching is only set up for first and second grade, at the same time, Martial Art is no longer available for the third and fourth grade. This kind of teaching situation is not propitious for the development of Martial Art culture and connotation. Therefore, in order to strengthen the teaching reform and optimize teaching mode, we should follow the rules of Martial Art education and characteristics of Martial Art teaching.

Martial Art can reflect our national unique values and outlook on life. Martial Art teachers in colleges and universities must correctly understand the importance of Martial Art teaching, inherit and carry forward its culture in the process of practical teaching, teach students the traditional Martial Art culture and enhance their patriotism as well as identity. Teachers are also suggested to strengthen their professional theoretical knowledge which is helpful to improve their professional level and conducive to better Martial Art teaching activities, promote the inheritance and development of Martial Art culture. Colleges and universities should carry out Martial Art teaching according to teaching needs and factual development situation, encourage teachers to use their spare time or winter and summer time to excavate and develop Martial Art work. This plays a core role in effectively promoting the development and inheritance of traditional Martial Art in colleges and universities. Through investigation, these are helpful to excavate and collate related teaching resources and able to improve teachers' professional level and scientific research ability, and promote the scientific development of Martial Art teaching in colleges and universities.

To improve Martial Art teaching in colleges and universities, we are required to strengthen the compilation of Martial Art theories and technologies. Compiling new teaching materials will be helpful for Martial Art teaching to develop in a directional way. To innovate Martial Art theories, 
combine teaching with the traditional culture and take teacher-explaining method will show the excellent traditional Martial Art culture of our country, strengthen students' practical operation, so that students will feel the charm of Martial Art activities, stimulate desire for knowledge and improve their Martial Art skills.

In order to carry out Martial Art teaching in colleges and universities, we should strengthen routine teaching and technical teaching, adopt diversified teaching methods, use multimedia and other equipments to assist teaching, enhance the explanation of Martial Art routines and apply videos to teach Martial Art skills to deepen students' understanding. Through the introduction of offensive and defensive teaching, we are able to stimulate students' interest in learning. During exercise time between classes, students can learn to perform, which is helpful to carry forward Martial Art learning spirits, enrich teaching contents and promote teaching innovation. Martial Art teaching in colleges and universities is required to absorb the results of western physical education without blind copy and learn to integrate. Positive innovation will promote the diversified development of Martial Art teaching, integrate Martial Art education with international education, expand Martial Art education resources and attach importance to personality education as well as the spread of harmony spirit. Moreover, we also are able to strengthen the exchange with foreign cultures, maintain our own postures, actively display our traditional culture, enhance national cohesion and stimulate students' national sense of pride. In the process of teaching, we are suggested to take culture as the outline, make traditional culture run through the whole teaching system and adopt the idea of making use of resources to promote the return of traditional Martial Art.

\section{Conclusion}

In summary, we can see that with the gradual development of market economy, accelerating economic globalization promotes mutual exchanges and collide among different cultures. Martial Art culture is Chinese outstanding traditional culture and is an important part of the development of Martial Art teaching in Colleges and universities, inheriting and carrying forward Martial Art spirits. To inherit Martial Art culture and promote the traditional Martial Art spirit, colleges and universities must give full play to the positive role of education, enhance teaching reform, cultivate patriotic and humanistic feelings of students, promote the effective extension of physical teaching and improve the comprehensive quality of students.

\section{References}

[1] Wang Baili. Absence and Remolding of Cultural Education in Martial Art Teaching. Journal of Shenyang Sport University [J], 2009, 28(6):117 20.

[2] Ma Mingda. Collection of Manuscripts on Swords [M]. Lanzhou: Lanzhou University Press, 2000. 376.

[3] The National Institute of Sports Teaching Material Committee. Chinese Martial Art Course [M]. Beijing: People 's Sports Press, 2003. 2.

[4] Huang Jinlai. "Educational Competition" and "National Culture" [J], Academic Forum, 2009(9):199 205. 